\title{
SYNTACTIC TRANSFER IN THE INITIAL STAGES OF ADULT THIRD LANGUAGE AND FOURTH LANGUAGE ACQUISITION
}

\author{
Mahbube Tavakol \\ Aliakbar Jabbari \\ University of Isfahan, Faculty of Foreign Languages \\ mahbubetavakol@gmail.com
}

Article received: 19 March 2015

Final proof received: 21 January 2016

\begin{abstract}
This paper elucidates the articulated proposals for the initial stages of adult third language (L3) syntactic transfer, addressing their application for L3 and the subsequent fourth language (L4) acquisition. The study was set to demonstrate empirical evidence in line with or against the tenets of the models and to indicate if and how syntactic transfer might obtain differently depending on the language being acquired- L3 vs. L4. The models to be tested were Full Transfer/Full Access (FT/FA), L2 Status Factor Hypothesis (LSFH), Cumulative Enhancement Model (CEM) and Typological Primacy Model (TPM). Following a principles and parameters framework, six parameters were selected to generate several language pairings and an adult female's L3 Italian and L4 German's early spontaneous productions of the selected features were audio-recorded. The accuracy levels with which the features were produced in tandem with the results of error analyses violated the positions of FT/FA as considered for L3/s acquisition and CEM and consistently identified Typological proximity and L2 status as affecting syntactic transfer during the early stages multilingual acquisition.
\end{abstract}

Keywords: multilingualism; third language acquisition; fourth language acquisition; syntactic transfer; initial state; typological proximity

While second language (L2) acquisition is a wellexplored territory, there seems to be a paucity of introspective data on multilingualism. Following the mainstream literature, there are radical differences of many kinds in the way L1 and L2 are acquired. But, is this also the case in L3 acquisition? Are there differences of any type (e.g. qualitative) between L2 and L3/Ln acquisition? In general, transfer or crosslinguistic influence (CLI) as theory-neutral cover terms refer to the L2er's initial hypotheses about a target non-primary language input which is composed from previously acquired languages and might be later restructured because of the learner's failure to assign a representation to the target input. From the vantage point of CLI, the main question is posed as if after a certain level of proficiency is achieved does L1 maintain its privileged role on the acquisition of the subsequent languages. In this connection, there might be also the possibility of L2 blocking L1's positive transferable effects to condition the initial stages transfer in adult multilingualism and one may also ponder on multilingual acquisition as if it could possibly be a cumulative process.

Several recent studies on L3 syntax have propagated that L2 is one source of transfer in L3 acquisition (Berkes \& Flynn, 2012; Flynn, Foley, \& Vinnitskaya, 2004; Leung, 2005, among others) and some studies even have indicated that L2 takes on a stronger role than L1 in the initial state of L3 acquisition (Bardel, 2010; Bardel \& Falk, 2007,
2012; Falk \& Bardel, 2011). Still other scholars proposed that the typological (structural) proximity of the languages involved determines the syntactic transfer in L3 and further expounded that the syntax of either the L1 or the L2 could be transferred to the early stages of L3 acquisition (Rothman, 2011; Rothman \& Amaro, 2010; Rothman, Iverson, \& Judy, 2011). In his article, Rothman (2013) maintains that the crux of the TPM is that structural proximity between the L3 and the L1 and/or the L2 determines L3 transfer. In addition to demonstrating empirical support for the TPM, he has articulated a proposal for how the mind unconsciously determines typological (structural) proximity based on linguistic cues from the L3 input stream at the onset of acquisition to determine holistic rather than reflexive transfer of one previous system be it L1 or $\mathrm{L} 2 / \mathrm{s}$.

Alternatively, it might be the case that there is neither non-facilitative transfer from the L1 nor from the L2 (Berkes \& Flynn, 2012; Flynn, Foley, $\&$ Vinnitskaya, 2004). To be clear then, one might ponder if and to what extent the articulated models and hypotheses of the initial stages of adult L3 morphosyntactic transfer can, in general, account for both L3 and L4 acquisition. Additionally, it should be noted that when it comes to L3 and L4 acquisition the interpretation of the specific interplay across the previously known languages and the Target Language (TL) becomes even more discerned than that of L2 acquisition since there are 
more than one source of material transfer at the multilingual learner's disposal.

Drawing on the generative framework, language is positioned as being governed by a set of highly abstract principles that provide parameters which are given particular settings in different languages. In the same spirit, this study is an endeavor to test the well-established L3 morphosyntactic transfer hypotheses for the initial state of L3 and L4 acquisition within the principles and parameters framework which by definition views human language as a complex set of principles each with one or more parameters of variation fixing of which determine the grammar of particular languages (Chomsky, 1981). As such, building upon the seminal, foundational studies (Cenoz, 2003; Flynn et al., 2004; Y. k. I. Leung, 2006; Rothman, 2011; Rothman \& Amaro, 2010; Schwartz \& Sprouse, 1996) and in tandem with the newly obtained data, the main purpose of this article is to test four multilingual acquisition proposals. To achieve this, several scenarios are considered to test each proposal in the early stages of L3 and L4 acquisition separately, relying on natural speech samples. At a more general level, the comparison of the early stages of L3 and L4 syntactic transfer could provide insights about possible variations in sequential multilingual acquisition as the case transits from one language to acquire a subsequent target language. Given that the foci of the present study deal directly with syntactic transfer as linked to the previous linguistic experience in L3 and L4 acquisition and, in particular, the extent of differences across L3 and L4 initial state syntactic transfer, six prominent syntactic parameters were carefully selected to generate language pairings and scenarios. The design of the study allowed the researcher to seek plausible answers to the following research questions: (1) What determines transfer in the initial state of L3 acquisition? (2) What determines transfer in the initial state of L4 acquisition? And (3) Are there any possible discrepancies between the initial states of adult L3 and L4 acquisition in terms of the type and extent of syntactic transfer?

Defining the labels L2, L3 and L4 acquisition

Roughly speaking, second language (L2) acquisition or SLA refers to the process of picking up another language after the L1 has been learned. As an interdisciplinary field of study, it is mainly concerned with nature of the hypotheses that learners come up with the rules of L2 which are either like those of the L1 or the TL. Throughout this study, second is not employed as an umbrella term to refer to all subsequent languages and is not intended to contrast with foreign. In this connection; however, no distinction is made between acquisition and learning and they are used interchangeably. Therefore, the label refers to English being acquired after L1 Persian in a foreign setting i.e. Iran. In the same spirit, a felicitous definition of multilingualism has been the subject of debate. In truth, multilingual acquisition is a field about which everyone seems to have an opinion. A number of researchers have explicitly or implicitly asserted that L3 acquisition is not another case of adult L2 acquisition (e.g. Bardel, 2010; Bardel \& Falk, 2007, 2012; Falk \& Bardel, 2011 Flynn et al., 2004; Leung, 2009).

Another view is that multilinguals having more than one language at disposal are more experienced learners in terms of knowing and applying social, cognitive and metacognitive strategies and as a result have advantages over bilinguals (Cenoz, 2003; Murphy, 2005). Broadly speaking, L3 acquisition is mainly concerned with the acquisition of any non-native language acquired beyond a chronologically true second language (L2) that is, the language acquired after L1, either in a naturalistic setting or within the context of classroom. In this study, the label is used to refer to the second non-native language acquired after English-Italian. In order to obtain a basis for discussing the situation of a quadrilingual/polyglot, we will use the term for an individual acquiring a language after a true L3. In fact, for the present purposes, we consider a polyglot as a person with knowledge of four or more languages and L4 (German) is strictly operationalised as the fourth language i.e. third non-primary language after L1 (Persian), acquired by the subject in a formal setting and it is approached from the view point of CLI. Given the definition of the labels L2, L3, and L4 acquisition, from a generative perspective, we could advocate the position that L3 and L4 acquisition have distinct initial states and unique paths of development from adult L2 acquisition. The following figure inspired by Hufeisen and Marx's (2007) model, clearly illustrates the distinctions amongst L2, L3 and L4 with respect to the components available at the learner's disposal at the onset of acquisition.

\section{L2 acquisition}

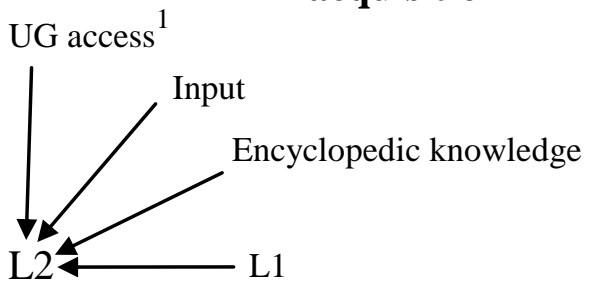

1. UG access is considered here as a prerequisite for language acquisition be it L1, L2/Ln or be it adult or child language acquisition. 


\section{L3 acquisition}

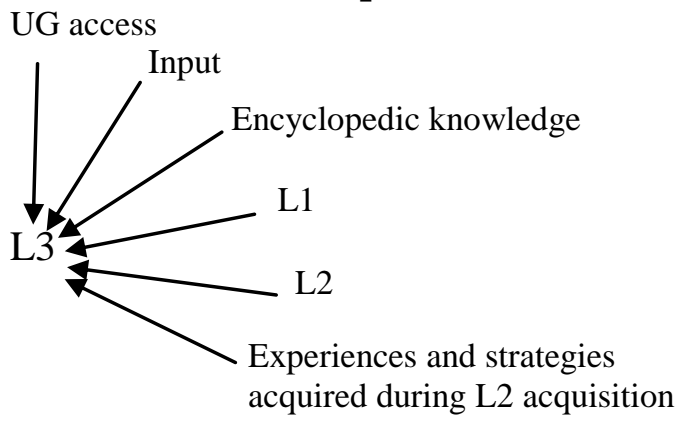

\section{L4 acquisition}

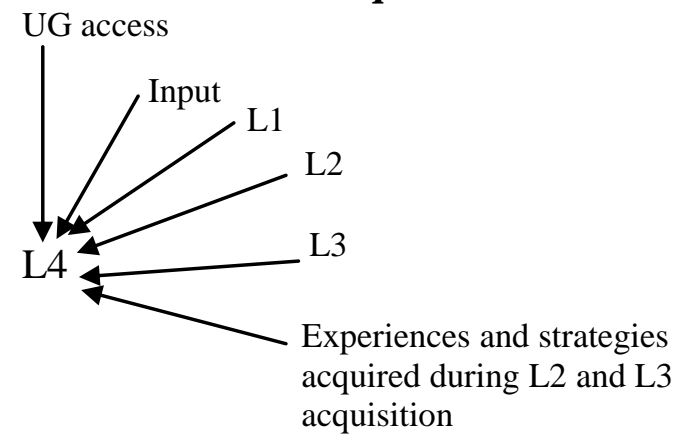

Figure 1. L2, L3 and L4 acquisition

\section{Multilingual acquisition transfer models}

In lieu of posing hypotheses, this study is an attempt to test the already proposed hypotheses for syntactic transfer in incipient L3 acquisition. The concept of transfer or CLI as a crucial construct of multilingual acquisition models, is, so far, approached from different, often opposing and seemingly incompatible perspectives. The first stance is Full Transfer/ Full Access as proposed by Schwartz and Sprouse (1996) which is an absolute L1 transfer position considering the fact that by initial state of adult $\mathrm{L} 2$ acquisition they refer to what the acquirer brings to the first moments of exposure to input that is the complete L1 system. The proponents claim that there will be access to universals and full transfer of an existing system (L1) at the very onset of acquisition. Here, I take a detour to note that we are not making a distinction between initial state and initial stages as made by Rothman (2013) and both are used to refer to the state where there has been minimally sufficient input for the learner as to choose one of the existing systems as the source of transfer. Schwartz and Sprouse (1996) further have argued that all syntactic properties of the L1 initially constitute a base for the new developing grammar with the involvement of Universal Grammar (UG). Some might quibble that FT/FA is, principally, an L2 transfer hypothesis but it could be argued that, albeit, the proponents have originally proposed the model to account for L2 they contend that L1 maintains its privileged role in the acquisition of all subsequent non-primary languages, that is, L2, $\mathrm{L} 3, \ldots, \mathrm{L}_{\mathrm{N}}$. Several recent studies on L3 syntax, on the other hand, have shown that L2 is one source of transfer. In Bardel and Falk (2007) the L2 transfer hypothesis was corroborated and explained by the L2 status factor, which had already been suggested by Williams and Hammarberg (1998) and Meisel (1983).

L2 Status Factor Hypothesis (LSFH) implies that the L2 can supersede the L1 as a significantly stronger source of transfer because of a higher degree of cognitive similarity between L2 and L3, than between L1 and L3 (Falk \& Bardel, 2010). As Rothman (2013) has rightfully pointed out, LSFH is essentially a strong hypothesis since its straightforward predictions are testable with different language pairings irrespective of their typology. The third position which rejects the notion of privileged transfer status for either of the two previously acquired systems, maintains that material can be transferred from either the L1 or L2. Such an approach is divided in the literature under two formal models. The first one is the so-called Cumulative Enhancement Model as proposed by Flynn et al. (2004) which assumes that either L1 or L2 may act as a source for transfer, that is, relevant L2 property won't transfer according to the CEM if it is not facilitative, either. This implies that CEM does not consider the possibility of negative transfer. This way, the proponents of CEM hold the view of an observable non-redundancy in multilingual acquisition the general idea behind which is that all the prior language acquisition experiences can facilitate subsequent language acquisition due to the human mind's repletion avoidance strategy. The second model, the Typological Primacy Model as stems from the collaborative work of Rothman and Amaro (2010) and later formalized in Rothman's article (2011), envisions accessibility to all sources of transfer in multilingual syntactic acquisition. However, given the limited cognitive resources during the course of forming initial L3/Ln input hypothesis, it maintains that ruling out the possibility of non-facilitative transfer is unrealistic. In simple words, they suggested a modified version of CEM where (psycho)typology may be a factor influencing the transfer source. That is, Like, CEM, this model also reconciles the juxtaposing view that $\mathrm{L} 1$ and $\mathrm{L} 2$ could both potentially affect the initial stages of $\mathrm{L} 3 / \mathrm{L}_{\mathrm{N}}$ acquisition and that the course of incipient multilingualism is conditioned by the cumulative effect of all the previously acquired languages; however, only TPM anticipates the possibility of non-facilitative transfer. The crux of the model is that the relative structural similarity between the L3 and one of the previously acquired languages, be it $\mathrm{L} 1, \mathrm{~L} 2, \ldots, \mathrm{Ln}$, is the determining factor for 
multilingual syntactic transfer which acknowledges the possibility of non-facilitative transfer in specific contexts.

\section{Syntactic Background}

To narrow the scope of the study down to some relevant parts of the languages involved in the present study at the syntactic level, six distinct parameters were selected as the main variables. Adopting a P\&P framework, the selected constructions were further divided under the two sub-headings of functional and lexical. This way instantiations of these parameters were chosen that resulted in several tangible scenarios each postulated to yield a verification or falsification of the proposed hypotheses of incipient multilingual acquisition with the language profile of this case study.

\section{Functional features}

\section{Null Subject Parameter (NSP)}

NSP is a highly-studied parameter of grammar the binary values of which explain the syntactic licensing of pronominal subjects in natural languages (Rothman \& Amaro, 2010). Generally speaking, based on word-order criterion, in configurational languages such as L2 English and L4 German, there is a fairly rigid word order based on a specifically ordered D-structure and likewise, all subjects must be overtly expressed, while, in prodrop languages such as Persian and Italian, finite verbs can have either an overt subject or a null pro subject. The following examples clearly show the difference between pro-drop and non-pro-drop languages of the present study.

Persian (L1):

a) mæn yek ketâb xând-æm.

I a book read-past. $1^{\text {st }}$ singular

'I read a book.'

b) yek ketâb xând-æm.

a book read-Past. $1^{\text {st }}$ singular

*'read a book.'

Italian (L2):

c) Io ho letto un libro.

I have read-past. $1^{\text {st }}$ singular a book

'I read a book.'

d) ho letto un libro.

have read-past. $1^{\text {st }}$ singular a book

*'read a book.'

\section{German (L4):}

e) Ich las ein Buch

I read-past. $1^{\text {st }}$ singular a book

'I read a book.'

f) *las ein Buch

Read-past. $1^{\text {st }}$ singular a book

*'read a book'

\section{The placement of negation}

Negation, the syntactic position of which interacts with other logical operators (Hojatollah Taleghani, 2006), is directly related to the so-called verbsecond (V2) parameter across languages. More precisely, the V2 property forces the non/thematic finite verb to occur not in initial or final position but in second position (Falk \& Bardel, 2010). The phenomenon of raising of the finite verb into a second slot has consequences for the placement of negation in declarative main clauses. Hence, there could be two main types of either post or pre-verbal negation and a partial pre/post verbal negation with respect to [+them] and [-them] verbs in language such as the non-V2 English.

\section{Post-verbal negation}

Due to the V2 property, German sentence negation is post-verbal in the main clause since all thematic and non-thematic verbs raise to a complementisers head (CP) while the negation remains in its original position above the VP. The followings are epitomes of the placement of negation in German.

a) Sie spricht nicht She speaks (+them) NEG

'She does not speak.'

b) Englisch ist nicht schwierig English COP (-them) NEG complicated 'English is not complicated.'

\section{Simultaneous pre and post-verbal negation}

While modern English is broadly SV (not V2) and is largely influenced by Romance languages, an earlier stage of English was V2, and some vestiges of the former V2 structure surface in a number of varying constructions. More precisely, verb raising in English as a non-V2 language distinguishes thematic from non-thematic verbs, and this has a bearing on the surface pattern of the English negative clause.

c) She does not speak

She Aux( -them) NEG V (+them)

\section{Pre-verbal negation}

Some Romance languages such as Italian due to their non-V2 properties negate the clause by employing only a pre-verbal negative marker.

d) (Lei) non parla (She) NEG speaks (+them)

'She does not speak.'

e) L'inglese non è complicato English NEG COP (+them) complicated 'English is not complicated.'

\section{Bound morphological negation}

A further distinction could, also, be made between two syntactic categories of bound morphological and syntactic negation. Syntactic negation is phonologically a separate word; while, bound negatives could be realized as portmanteau forms 
and make a prosodic unit with the verb. Negation in Persian is a preverbal negative affix. It is represented by the prefix $n a-/ n e$ - at the beginning of the verbal stem in simple verbs and at the beginning of light verbs in complex predicates.

Persian:

f) u: sohbæt ne-mi-kon-æd (+them) s/he speak NEG-aspect marker- do- $3^{\text {rd }}$ person singular. present 'she does not speak'

g) engelisi pichide ni-st (-them)

English complex NEG-COP

'English is not complicated.'

To set out the language pairings of the present study, both the position of negation and bound/syntactic distinction are considered. Relying on the pre/post verbal negation spectrum, German has a strict post verbal negation, English divulges a [+them]/[-them] distinction with pre [+them] verbal negation and post [+them] verbal negation. Italian has a rigid preverbal negation with the marker, non. Persian, albeit has a preverbal negation for [+them]/[-them] verbs, behaves in a completely distinguishing manner with respect to bound/syntactic distinction in that the clauses are made negative using a bound morpheme - na/ne.

\section{Definiteness}

Roughly speaking, definiteness is a feature of NPs, distinguishing between entities that are specific and identifiable in a given context and entities which are not. This feature is overtly realized in the phonetic form (PF) in some languages while in others it is solely interpretable in the logical form (LF). From the view point of Rezai and Jabbari (2010), embracing the classic 'uniqueness' characterization of the difference between definite and indefinite NPs, definiteness is informally defined as the speaker and hearer presupposing the existence of a unique individual in a set denoted by the NP.

\section{Definiteness in Persian and English}

Definiteness in Persian is generally discussed in the context of two morphemes, râ and i. The former, according to Ghomeshi (2003), is a case marker that appears on definite direct object and attaches syntactically to DPs; while the latter is the Persian indefinite. While there is no overt article or morphological inflection in Persian denoting a definite context, in English, the article 'the' instantiates the semantic feature of definiteness and since it has no descriptive content it can modify or mark any type of NP out as definite (Rezai \& Jabbari, 2010).

\section{Definiteness in Italian and German}

While in English the definite article has only one form, in Italian, it has various forms according to the gender, number, and first letter of the noun or adjective it precedes. The definite articles in German are, in turn, declined and the inflected forms acknowledge the number, the case and the grammatical gender of the corresponding noun. Simply put, in German, all NPs can be marked as [+definite] by the definite articles which differ based on the gender, number and case of the following NP. The articles have the same plural forms for all three genders.

\section{Lexical features \\ OV property}

Related to V2 parameter of the main clauses is the so-called OV property of subordinate clauses according to which the finite verb is in a final position, thus it does not move out from its base position. Apart from free relative clauses, a critical feature of non/restrictive relative clauses in the natural languages is the relative position of finite verb and its complement which is syntactically referred to as object-verb $(\mathrm{OV})$ property.

\section{RCs in Persian and German}

One of the most conspicuous features of German is the word order asymmetry between main and subordinate clause, with respect to the placement of the finite verb, as illustrated in (1) and (2).

a) Ich weiß, dass er es isst I know, that he it eats 'I know that he eats it.'

b) Er isst es 'He eats it.'

In the relative clause in (1), the finite verb is in a final position, thus it does not move out from its base position (OV property); but in the main clause (2) the verb is in a second position (the V2 property). Assuming the basic word order in Persian, where the object immediately precedes the verb and indirect objects also precede the verb being represented by prepositional phrases (PP), Persian does show the same OV property in relative clauses of either type; however, it always has the same basic structure, in a subordinate or a main clause. Simply put, in both Persian and German the verb is basegenerated to the right, a position in which it stays in RCs.

Persian:

Bærâdær-e mæn, ke shætranj bâzi mi-kon-æd, moælem æst.

Brother-Ez my, COMP chess play-present. $3^{\text {rd }}$ singular teacher COP

'My brother, who plays chess, is a teacher.'

German:

Mein Bruder, der Schach spielt, ist ein Lehrer. My brother, COMP chess plays, COP a teacher My brother, who plays chess, is a teacher. 


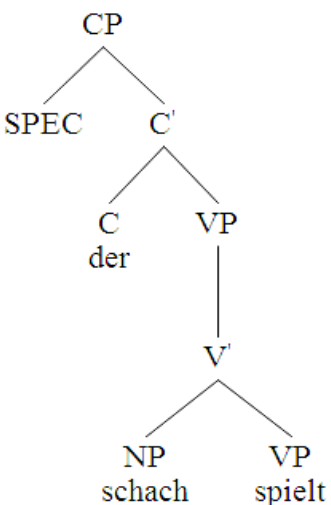

Figure 2. German relative clauses' structure $\mathrm{RCs}$ in English and Italian

In English and Italian relative clauses, the finite verb occupies second position before the complement and after the s-pro.

Italian and English:

Mio fratello, che gioca a scacchi, è un insegnante. My brother, COMP plays chess, COP a teacher 'My brother, who plays chess, is a teacher.'

\section{Attributive adjectives}

An adjective is a word whose main syntactic function is to modify an attribute of the NP of which it is a part. The position of an attributive adjective as the head of NP set two options where the head noun ends up occupying a position either to the left of the adjective as is the case in Persian (L1) and Italian (L2) or to the right of the adjective like in English (L2) and German (L4) structures.

\section{Adjective position in English and German}

In English, the adjectives are pronominal, that is, they precede the noun they modify. The construction of attributive adjectives is the same in English and German. It is a standard T-G practice to derive attributive adjectives from predicative adjectives embedded in relative clauses. Three transformational rules must be employed in passing from deep structure (DS) to surface structure (SS) (James, 1980).

English (L2):

The yellow car

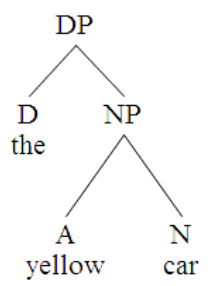

Figure 3. Attributive adjective's position in English German (L4):

Das gelbe Auto

'The yellow car'

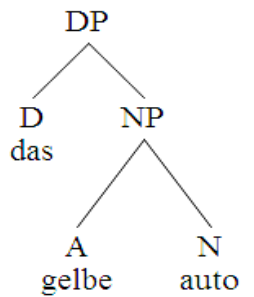

Figure 4. Attributive adjective's position in German Adjective position in English and German

The analogous Persian and Italian strings differ from the English and German ones in dispensing with the adjective preposing transformation in a way that attributives normally follow the modified noun in these languages. Although Persian is verb-final at the sentential level, it behaves like head-initial languages in NPs and PPs. Thus, the head noun in an NP is often followed by the modifiers and possessors, and the preposition precedes the complement NP.

Italian:

La macchina gialla

the car yellow

Persian:

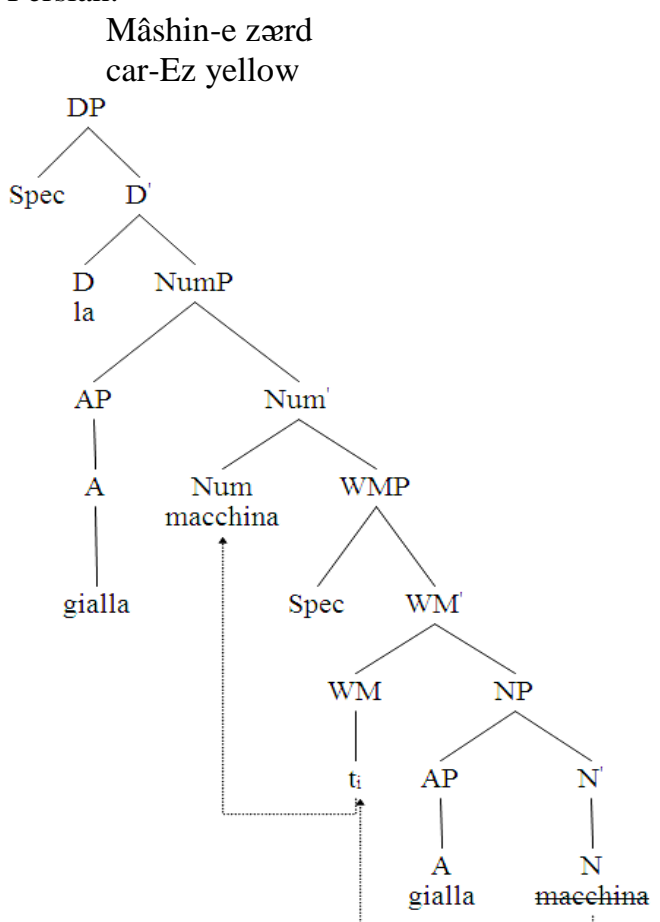

Figure 5. The position of attributive adjective post to noun raising in Italian

The following table is a holistic account of the desired language pairings and parametric variations amongst the languages involved. 
Table 1. The Desired Language Pairings Based on the Selected Parameters

\begin{tabular}{|c|c|c|c|c|c|c|}
\hline & \multicolumn{2}{|c|}{ Features } & Persian & English & Italian & German \\
\hline \multirow{2}{*}{ 氖 } & \multicolumn{2}{|c|}{ OV property } & Comp + finite $\mathrm{V}$ & finite $V+$ Comp & finite $V+$ Comp & Comp + finite $\mathrm{V}$ \\
\hline & \multicolumn{2}{|c|}{ Attributive adjectives } & Noun + adjective & $\begin{array}{l}\text { Adjective + } \\
\text { noun }\end{array}$ & Noun + adjective & Adjective + noun \\
\hline \multirow{4}{*}{ } & \multirow{2}{*}{ Negation } & [+them] & Pre-V/morpheme & Pre-V/syntactic & Pre-v/syntactic & Post-V/syntactic \\
\hline & & [-them] & Pre-V/morpheme & Post-V/syntactic & Pre-v/syntactic & Post-V/syntactic \\
\hline & \multicolumn{2}{|c|}{ Null-subject } & [+null subject] & [-null subject] & [+null subject] & [-null subject] \\
\hline & \multicolumn{2}{|c|}{$\begin{array}{c}\text { DAs in nominative } \\
\text { case }\end{array}$} & No DA & One DA 'the' & $\begin{array}{c}\text { DAs based on } \\
\text { number \& gender }\end{array}$ & $\begin{array}{c}\text { DAs based on } \\
\text { number \& gender }\end{array}$ \\
\hline
\end{tabular}

1. Note: Italics and underline are used to differentiate among the different parameter settings

\section{METHOD}

\section{The subject of the study}

In terms of the type of multilingual, the case was an early (not late) multilingual in the initial stages of L3 and L4 acquisition and in terms of the proficiency level of bilingualism involved in L3 and L4 process she was an educated Persian (L1) native speaker with high command of English (L2). She was a 26-year-old female who was living in Yazd province, Iran, at the time of data collection. She was a successful L1 Persian learner of L2 English at the early stages of L3 Italian and L4 German acquisition. Throughout the study, the subject received in-home, private tutor by the same instructor, who was not a native speaker of either of the languages but had a high command of both of them and the learning situation was approximately the same for both languages, that is, the same room, the same instructor, approximately the same time of the day and the same type of teacher-student interaction.

Table 2. The Subject's Language Profile

\begin{tabular}{llccc}
\hline Language profile & First language & Second language & Third language & Fourth language \\
\hline & Persian & English & Italian & German \\
\hline Language typology & Indo-Iranian & Germanic & Romance & Germanic \\
\hline Level of Proficiency & Native language & $\mathrm{C} 2$ & $\mathrm{~A} 2$ & $\mathrm{~A} 2$ \\
\hline
\end{tabular}

This instrumental case study focused on one single case to make inferences about syntactic transfer during L3 and L4 acquisition. It was associated with a quantitative paradigm, aiming at provision of statistical, panoramic pictures of the concerned linguistic trends, that is, each variable in the present study (NSP, the placement of negation, definiteness, OV property, attributive adjective and the copula) represented a nominal scale in percentage terms. While the study seems at least partially longitudinal in nature, it was more of a cross-sectional research, giving a snapshot-like analysis of the target phenomenon. It enjoys, further, an exploratory-qualitative-statistical design. Exploratory in terms of research type, because in lieu of investigating some clearly refined research questions and hypotheses it aims at testing several proposed hypotheses in a heuristic manner.

\section{Data collection procedure}

The major instrument adopted for the purpose of data collection was record examination. The data reported, were collected approximately 2 times a week, covering a period of 6 months which was divided into two approximately equal intervals of three months. Each interval consisted of nearly a total of twenty 90-minute sessions. All the sessions were recorded using a Sony digital recorder and transferred to the computer to be transcribed and investigated. There were two sets of data: 21 audiofiles covering the learner's earliest Italian and 24 audio-files covering the learner's earliest German.

Table 3. Input Schedules for Data collections

\begin{tabular}{llclc}
\hline Input & Period & Total sessions & Sessions' interval & Data Collection \\
\hline Italian & May 21, 2012- August 5, 2012 & 21 & Twice a week & A \\
\hline German & August 23,'12-November15, '12 & 24 & Twice a week & B \\
\hline
\end{tabular}

The above table presents a rough idea of the amount of exposure to Italian and German. But, the process of transcribing and analyzing naturalistic samples is extremely time-consuming and often unreliable. Therefore, the CHAT system was employed to provide a standardized format for producing computerized transcripts of face-to-face conversational interactions. The subject was 
exposed to TLs without any linguistic awareness and the features were selected by the end of instruction after conducting error analyses of the parser's productions using the already-made corpora.

\section{Scoring procedure}

Obligatory occasion analysis (OOA) is an approach to the analysis of the learner's interlanguage data which is clearly positioned by Brown (1973). According to Ellis and Barkhuizen (2005), the principal procedures in OOA based on which one can observe the learner's learning trajectory, is as follow. First, samples of learner's spontaneous productions are collected. Second, obligatory occasions for the use of specific TL features are identified. Third, the percentage of accurate use of the feature is then calculated by establishing whether the feature in question has been supplied in all the obligatory contexts in which it is required. The subject's accuracy in using every linguistic feature was, therefore, calculated by means of the following formula:

\section{(n) correct suppliance in contexts}

\section{(x) total obligatory contexts $\times 100=\%$ accuracy}

The criterion level of accuracy of production was set at 80 percent. Therefore, if the learner achieved accuracy score of 80 percent or higher, the feature would be counted as being 'acquired'. But, OOA takes no account of when the learner supplies a feature in a non-obligatory context. The acquisition of a feature requires mastering not only when to use it but also when not to use it. To take account of overuses a number of researchers have suggested a procedure known as target-like use analysis (e.g. Pica, 1983). Therefore, to take account of over-suppliance of s-pros in Italian, the researcher has employed the TLU analysis with the following formula:

(n) correct suppliance in contexts

(x) obligatory + (y)suppliance in contexts non-obligatorycontexts

In this formula the level of accuracy is set at 80 percent, as well.

\section{Scenarios}

Considering the variables, several scenarios were predicted to test each proposal for the onsets of both L3 and L4 acquisition. The scenarios were operationalised through the quantification of the study's variables. The following table summarizes the scenarios predicted to test each proposal.

Table 4. Scenarios to Test the Models for Initial Stages of L3 Syntactic Transfer

\begin{tabular}{|c|c|c|c|}
\hline Language & Hypothesis & Scenario & Feature(s) \\
\hline L3 & FT/FA & $\mathrm{L} 3=\mathrm{L} 1 \neq \mathrm{L} 2$ & NSP, Attributive Adjective \\
\hline L3 & LSFH & $\mathrm{L} 3=\mathrm{L} 2 \neq \mathrm{L} 1$ & OV property, thematic verbs' negation \\
\hline L3 & CEM & $\mathrm{L} 3=\mathrm{L} 1 \neq \mathrm{L} 2 ; \mathrm{L} 3=\mathrm{L} 2 \neq \mathrm{L} 1$ & $\begin{array}{l}\text { The copula, NSP, Attributive Adjective, } \\
\text { OV property, thematic verbs' negation }\end{array}$ \\
\hline L3 & TPM & $\mathrm{L} 3=\mathrm{L} 2 \neq \mathrm{L} 1$ & OV property, thematic verbs' negation \\
\hline L4 & FT/FA & $\mathrm{L} 4=\mathrm{L} 1 \neq \mathrm{L} 2, \mathrm{~L} 3$ & OV property \\
\hline L4 & LSFH & $\mathrm{L} 4=\mathrm{L} 2 \neq \mathrm{L} 1, \mathrm{~L} 3$ & $\begin{array}{l}\text { NSP, attributive adjective, non-thematic } \\
\text { verbs' negation }\end{array}$ \\
\hline L4 & CEM & $\begin{array}{c}\mathrm{L} 4=\mathrm{L} 1 \neq \mathrm{L} 2, \mathrm{~L} 3 ; \mathrm{L} 4=\mathrm{L} 2 \neq \mathrm{L} 1 \\
\mathrm{~L} 3 ; \mathrm{L} 4=\mathrm{L} 3 \neq \mathrm{L} 1, \mathrm{~L} 2\end{array}$ & $\begin{array}{l}\text { The copula (part A), OV property; NSP, } \\
\text { attributive adjective, non-thematic verbs' } \\
\text { negation; definiteness (part B) }\end{array}$ \\
\hline L4 & TPM & $\mathrm{L} 4=\mathrm{L} 2 \neq \mathrm{L} 1, \mathrm{~L} 3$ & $\begin{array}{l}\text { NSP, attributive adjective, non-thematic } \\
\text { verbs' negation }\end{array}$ \\
\hline
\end{tabular}

\section{RESULTS AND DISCUSSION}

In order to quantify the instances of a feature's production in terms of accuracy level using the given formulas, responses were coded as 'correct' or 'incorrect'. In the case null subjects, the instances of suppliance versus non-suppliance in both obligatory and optional contexts were counted to generate the accuracy level in percentage terms. In what follows, the results of recordings' examinations are presented in great detail.

\section{Null-subject parameter}

Analyzed utterances in Italian:

Declarative main clauses with minimum length of one word

- Obligatory Contexts 1 (OC1): need an overt subject pronoun (s-pro, afterwards) 
- Obligatory Contexts 2 (OC2): no need of an overt s-pro (there is no pronoun to be supplied)

- Optional contexts (OPC): no need of an overt s-pro

- Target-Like Use (TLU): suppliance of subject pronouns in $\mathrm{OC} 1$, non-suppliance of subject pronoun in $\mathrm{OC} 2$ and nonsuppliance of subject pronoun in OPC

- Non-Target-Like Use (NTLU): nonsuppliance of subject pronouns in $\mathrm{OC} 1$, suppliance of subject pronouns in $\mathrm{OC} 2$ and OPC

\section{Analyzed utterances in German:}

Declarative main clauses with minimum length of one word.

- Obligatory contexts: need a s-pro in the PF
- TLU: suppliance of the s-pro in all the obligations

- NTLU: non-suppliance of the s-pro in the obligatory contexts

In Italian corpus, it was decided that the use of s-pros should be counted in both obligatory and non-obligatory contexts in the initial state of acquisition. In a few cases, it was obligatory not to supply the s-pro like in asking or expressing the time (Che ora é? ${ }^{*}$ what time is?); yet, in most contexts it was optional either to supply it or not. However, the TLU of the language would be culminated only when the feature was not supplied in optional contexts as the native speakers of Italian do not supply the pronoun in optional contexts.

Table 5. Null Subject Pronouns

\begin{tabular}{lllllcr}
\hline Corpus & OC & OPC & TLU & NTLU & Suppliance in OPC & Accuracy \% \\
\hline L3 Italian & 14 & 61 & 19 & 56 & 53 & 28.35 \\
\hline L4 German & 59 & - & 51 & 8 & - & 86.44 \\
\hline
\end{tabular}

Note: the accuracy level for this feature is generated using TLUA formula in L3 and OOA in L4

Using TLU formula, non/supliance of the Italian subject pronouns in non/obligatory contexts were counted to generate the accuracy percentage. Comparing the accuracy level set for the study and the one obtained, it is indicated that the feature is not accurately acquired in L3. In truth, the results of error analyses reported the subject to consistently supply the subject pronouns in optional contexts. This suggests that there is a desire to suppress L1 as being non-foreign while it is the most economical source of transfer and to rely rather on L2 in which the s-pro is obligatory. In the case of L4 German spro is obligatory and the number of optional contexts equals zero. As opposed to Italian, the accuracy percentage reported in L4 gives the impression that L2 can take on stronger role than L1 as supplier and is, tout court, the main source in syntactic positive/negative transfer. In line with the results obtained here but with different language pairings, Rothman and Caberelli Amaro (2010) reported L2 Spanish null subjects to be transferred to both L3 French (non-null-subject) and L3 Italian which again shows the strong role of L2.

\section{The placement of negation}

Analyzed utterances in Italian:

Clauses containing at least a verb and a negative marker

- Correct placement of negation in terms of \pm thematic verbs

- TLU: pre-verbal negation of \pm thematic verbs

- NTLU: post-verbal negation of \pm thematic verbs

Analyzed utterances in German:
Clauses containing at least a verb and a negative marker

- Correct placement of negation in terms of \pm thematic verbs

- TLU: Post-verbal negation of \pm thematic verbs

- NTLU: pre-verbal negation of \pm thematic verbs

Here, the subject has applied the pre-verbal negation rule correctly with respect to thematic verbs in L3 which is shared with L2 English, while analogous to English L2 in which non-thematic verbs are negated post verbally, the learner tends to transfer post-verbal placement of negation for nonthematic verbs. A seemingly interesting case of negation was noticed regarding the subject's performance in the placement of negation in the case of the verb 'have' in Italian which similar to English is used both as non/thematic. Surprisingly, whenever the learner has produced a negative utterance containing 'have' as a lexical verb she tended to produce preverbal negation which has been considered to be TLU and when producing an utterance with 'have' functioning as an auxiliary it has been negated post-verbally. In the case of German negation, in the onset of acquisition the learner has used the English 'not' instead of 'nicht', therefore, the question is raised that, if the learner has already two negative markers at disposal ('not' and 'non'), how come she has resorted to the English negative marker? Also, comparing the overall accuracy levels across L3 and L4, it could be simply inferred that L4 is acquired more accurately than L3. 
Definiteness

Analyzed utterances in Italian and German:
Utterances containing at least an NP in nominative case which should be marked out as definite

Table 6. Negation placement

\begin{tabular}{|c|c|c|c|c|c|c|}
\hline Corpus & Feature & $\operatorname{Record}(\mathbf{s})$ & Total & TLU & NTLU & Accuracy \% \\
\hline \multirow[b]{2}{*}{ L3 Italian } & +thematic ${ }^{\mathrm{a}}$ & $11,14,15$ & 34 & 29 & 5 & 85.29 \\
\hline & - thematic $^{\mathrm{b}}$ & $9,10,11$ & 25 & 11 & 14 & 44 \\
\hline \multirow{4}{*}{ L4 German } & \pm thematic & $9,10,11,14,15$ & 59 & 40 & 19 & 67.79 \\
\hline & +thematic & $6,7,13$ & 24 & 15 & 9 & 62.70 \\
\hline & -thematic & $6,7,11,13$ & 27 & 23 & 4 & 85.19 \\
\hline & \pm thematic & $6,7,11,13$ & 51 & 38 & 13 & 74.50 \\
\hline
\end{tabular}

a: Note: +thematic verbs $=$ lexical verbs , b: Note: - thematic verbs $=$ be, have, auxiliaries and the modal can

syntactic licensing of an overt counterpart of the definiteness marker 'the' based on number and gender

- TLU: using the right form of DA to mark an NP as +definite

- NTLU: using the wrong form of DA to mark an NP as +definite

Table 7. Definite articles

\begin{tabular}{llccrr}
\hline Corpus & \multicolumn{1}{c}{ Record(s) } & Total & TLU & NTLU & \% \\
\hline L3 Italian & $16,17,20,21$ & 87 & 76 & 11 & 87.35 \\
\hline L4 German & $2,3,4,7,10$ & 64 & 43 & 21 & 67.18 \\
\hline
\end{tabular}

The accuracy level presented for the production of Italian definite articles is well expressive of the fact that the structure in L3 potentially is accurately acquired and has the necessary condition to be transferred to L4. However, to the researchers' surprise, the learner not only has had problems in supplying various forms of the German articles but also in some contexts she has used the English definite article 'the' for the NPs like 'the Frau' which was supposed to be 'die Frau'. In addition, the results of the error analyses also suggest that the acquirer faced difficulty denoting a definite context using the correct declined forms of the articles in terms of number and gender. This reveals that even the recently acquired language cannot suppress the previous ones to condition the syntactic transfer and L2 could possibly maintains its privileged role in L4 acquisition which could be taken as evidence against what is purported by CEM to be the principle of multilingual syntactic transfer. Here, one might argue that without a mirror image participant as a point of comparison That is, an L1 Persian/L2 English learner, how can you claim such a thing and since we are aware of this limitation of our study, we must be cautious and keep this at the level of a conjecture.

\section{OV property}

Analyzed utterances in Italian:

Embedded clauses containing at least a relative pronoun functioning as a subject, a finite verb and a complement

Non/restrictive relative clauses (RCs) with 'verb + complement' structure

- TLU: non/restrictive RCs with finite verb followed by a complement

- NTLU: non/restrictive RCs with finite verb preceded by a complement

Analyzed utterances in German:

Embedded clauses containing at least a relative pronoun functioning as a subject, a finite verb and a complement

Non/Restrictive relative clauses with 'complement + verb' structure (OV property)

- TLU: non/restrictive RCs with finite verb preceded by a complement

- NTLU: non/restrictive RCs with finite verb followed by a complement

Table 8. OV property

\begin{tabular}{lllccrr}
\hline Corpus & Feature & Record(s) & Total & TLU & NTLU & \\
\hline L3 Italian & OV Property & $13,14,16,19$ & 23 & 19 & 4 & 82.60 \\
\hline L4 German & OV Property & $14,17,19$ & 19 & 11 & 8 & 57.89 \\
\hline
\end{tabular}

A comparison of the accuracy levels and an investigation of the errors committed by the learner again revealed how L2 affects the acquisition of syntactic structures at the initial state of L3 and L4 acquisition.
Attributive adjectives

Analyzed utterances in L3:

Utterances containing at least an adjective as a modifier and a modified NP 
- Modification with adjectives in the second position - after the noun

- TLU: adjectives followed the modified NP

- NTLU: adjectives preceded the NP

Analyzed utterances in German:

Utterances containing at least an adjective as a modifier and a modified NP

Modification with adjectives in the first position - before the noun as in English

- TLU: adjectives precede the modified nouns

- NTLU: adjectives follow the noun like in English

Table 9. Attributive Adjective

\begin{tabular}{lccccr}
\hline Corpus & Record(s) & Total & TLU & NTLU & \% \\
\hline L3 Italian & $13,14,16,19$ & 32 & 9 & 23 & 28.12 \\
L4 German & $14,17,19$ & 29 & 25 & 4 & 86.20 \\
\hline
\end{tabular}

In this case, a simple comparison of the accuracy levels and the type of errors committed by the learner could help us glean a miscellany of substantive facts. Note that whereas the feature is not accurately acquired in Italian L3, the results of OOA show a high level of accuracy in German where the order of adjective placement is the same as English L2. It could be contended that the structure is here transferred from L2 to both L3 and L4. Thus it could be argued that in this case like the previously presented ones, the transfer of L2 syntax overrides or say block transfer of L1 syntax, even though transfer from Persian L1 would yield a target-like structure in Italian.

\section{CONCLUSION}

This study set forth the possibility of testing the major multilingual acquisition hypotheses in the contexts of L3 and L4 acquisition based a number of scenarios. With respect to the general principles of FT/FA as applied for L3 and L4 acquisition, it could be argued that; although, the influences of first language in subsequent language acquisition cannot be totally neglected, one cannot really claim that it inevitably and always remains the main dominant source for the acquisition of all the languages after L1. That is, there is complete transfer as opposed to property-by-property transfer, by virtue of similar structures being positively and non-similar structures being negatively transferred in the initial state, but, it is not necessarily from L1 when the learner moves from L2 to acquire L3/Ln. As such, we argue that L1 does not exert such strong influence in multilingual acquisition, regardless of the type of syntactic feature in terms of obligatory/non-obligatory distinction.

The present study, also, argues in favor of L2 complete syntactic transfer based on the documented evidence on the occurrence of a total of 6 negatively and 7 positively transferred properties in various forms from L2 to L3 which were found relying on the spontaneously-produced spoken data. By complete, we mean that due to the higher degree of cognitive similarity between L2 and L3/s than between $\mathrm{L} 1$ and $\mathrm{L} 3 / \mathrm{s}$, the entire $\mathrm{L} 2$ is transferred to the initial states of both L3 and L4 which in some contexts results in non-facilitative transfer in the sense of Full Transfer. In similar vein, the effects of L2 status could also be attributed to typology as well. In line with Rothman (2013) stipulative claims, L2 (structurally closer to L3 and typologically closer to L4 than L1) transferred holistically as opposed to reflexively or structureby-structure in the sense that CEM advocates. The so-called CEM for the initial stages of adult L3 syntactic transfer is based on the idea of nonredundancy and it claims that all the previously acquired languages modify the course of multilingual acquisition in a positive way or they remain neutral; however, the results reported in this paper suggest that such a reflexive transfer will not be always the case. In fact, strong evidence of nonfacilitative transfer from the previously acquired languages, mostly L2, in contexts where the target structure did not resemble that of L2, are in conflict with the principal concerns at the heart of CEM.

Investigating the gender and number concord of L4 definite articles on the analogy of gender and number concord of Italian definite articles, provided us with the evidence of L2 suppressing the role of L3 in terms of the subject's frequent use of the English article 'the' to indicate definiteness in German. This provided further counter evidence for CEM. But still it must be kept in mind that several other psychological and sociolinguistic factors such as age, gender, proficiency level, setting, sequential vs. simultaneous acquisition, are involved. Our detailed compilation of L3 and L4 transferred positive/negative properties offered an insight into the nature of CLI and provided new instances that L2 and/or typological proximity do play a big role in the initial stages of adult L3 and L4 syntactic transfer. As such, it offered valuable insights into the nature of the multilingual or polyglot mind and the conditions at which L2 and/or typology is being activated. However, due to the design of the current case study it was not possible to tease apart the effects of L2 status factor from typological proximity. Hence, subsequent testing and empirical investigation is demanded to tease apart the effects of L2 status factor and typology on L3/Ln 
acquisition. Ultimately, though we cannot claim a qualitative difference between L3 and L4 we argue in favor of a difference in the extent of transfer between L3 and L4 with L4 being, overall, less influenced, in terms of negative transfer, by the previously acquired languages by virtue of the features being acquired with higher levels of accuracy comparing to the ones in L3.

\section{REFERENCES}

Bardel, C. (2010). The lexicon of advanced L2 learners. High-level proficiency in second language use. Berlin: Mouton de Gruyter.

Bardel, C., \& Falk, Y. (2007). The role of the second language in third language acquisition: the case of Germanic syntax. Second Language Research, 23(4), pp. 459-484.

Bardel C., \& Falk Y. (2012). The L2 status factor and the declarative/procedural distinction. In Cabrelli Amaro J., Flynn S., Rothman J. (Eds.), Third language acquisition in adulthood (pp. 61-78). Amsterdam, The Netherlands: John Benjamins.

Berkes, É., \& Flynn, S. (2012). Further evidence in support of the Cumulative-Enhancement Model: CP structure development. In Cabrelli Amaro J., Flynn S., Rothman J. (Eds.), Third language acquisition in adulthood (pp. 143164). Amsterdam, The Netherlands: John Benjamins.

Brown, R. (1973). A first language: The early stages: Harvard U. Press.

Cenoz, J. (2003). The role of typology in the organization of the multilingual lexicon. The multilingual lexicon, 23(4), pp. 103-116.

Chomsky, N. (1981). Knowledge of language: Its elements and origins. Philosophical Transactions of the Royal Society of London. B, Biological Sciences, 295(1077), pp. 223234.

Ellis, R., \& Barkhuizen, G. P. (2005). Analysing learner language: Oxford University Press, USA.

Falk, Y., \& Bardel, C. (2010). The study of the role of the background languages in third language acquisition. The state of the art. IRALInternational Review of Applied Linguistics in Language Teaching, 48(2-3), pp. 185-219.

Falk, Y., \& Bardel, C. (2011). Object pronouns in German L3 syntax: Evidence for the L2 status factor. Second Language Research, 27(1), pp. 59-82.

Flynn, S., Foley, C., \& Vinnitskaya, I. (2004). The Cumulative-Enhancement Model for Language Acquisition: Comparing Adults' and Children's Patterns of Development in First, Second and Third Language Acquisition of Relative Clauses. International Journal of Multilingualism, 1(1), pp. 3-16.
Ghomeshi, J. (2003). Plural marking, indefiniteness, and the noun phrase. Studia Linguistica, 57(2), pp. 47-74.

Taleghani, A. H. (2006). The interaction of modality, aspect and negation in Persian. University of Arizona: Unpublished Ph.D. Dissertation

Hufeisen, B., \& Marx, N. (2007). How can DaFnE and EuroComGerm contribute to the concept of receptive multilingualism? Theoretical and practical considerations. Receptive Multilingualism. Linguistic analyses, language policies and didactic concepts.

Amsterdam/Philadelphia: John Benjamins, pp. 307-321.

James, C. (1980). Contrastive Analysis.

Leung, Y.-k. I. (2005). L2 vs. L3 initial state: A comparative study of the acquisition of French DPs by Vietnamese monolinguals and Cantonese-English bilinguals. Bilingualism: Language and Cognition, 8(01), pp. 39-61.

Leung, Y.-k. I. (2009). Third language acquisition and universal grammar (Vol. 37): Multilingual Matters.

Leung, Y. k. I. (2006). Full transfer vs. partial transfer in L2 and L3 acquisition. Inquires in Linguistic Development. In Honor of Lydia White, 7(12), pp. 157-188.

Meisel, J. M. (1983). Transfer as a second-language strategy. Language \& communication, 3(1), pp. 11-46.

Murphy, S. (2005). Second language transfer during third language acquisition. Teachers College, Columbia University Working Papers in TESOL \& Applied Linguistics, 3(1), pp. 1-18.

Pica, T. (1983). Adult acquisition of English as a second language under different conditions of exposure. Language learning, 33(4), pp. 465497.

Rezai, M., \& Jabbari, A. (2010). The Acquisition of Definiteness Feature by Persian L2 Learners of English. Journal Of Teaching Language Skills (JTLS) (Journal Of Social Sciences And Humanities).

Rothman, J. (2011). L3 syntactic transfer selectivity and typological determinacy: The typological primacy model. Second Language Research, 27(1), pp. 107-127.

Rothman, J. (2013). Linguistic and cognitive motivations for the Typological Primacy Model (TPM) of third language (L3) transfer: Timing of acquisition and proficiency considered. Bilingualism: Language and Cognition, 17(2), pp. 1-12.

Rothman, J., \& Amaro, J. C. (2010). What variables condition syntactic transfer? A look at the L3 initial state. Second Language Research, 26(2), pp. 189-218.

Rothman, J., Iverson, M., \& Judy, T. (2011). Introduction: Some notes on the generative 
Tavakol and Jabbari, Syntactic transfer in the initial stages of adult third...

study of L3 acquisition. Second Language Research, 27(1), pp. 5-19.

Schwartz, B. D., \& Sprouse, R. A. (1996). L2 cognitive states and the full transfer/full access model. Second language research, 12(1), pp. 40-72.
Williams, S., \& Hammarberg, B. (1998). Language

switches in L3 production: Implications for a polyglot speaking model. Applied linguistics, 19(3), pp. 295-333. 